\title{
Effect of chemotherapeutic drugs on telomere length and telomerase activity
}

\author{
Alejandro D. Bolzán \\ Laboratory of Cytogenetics and Mutagenesis, Multidisciplinary Institute of Cell Biology (IMBICE, CICPBA-UNLP-CONICET La \\ Plata), P.O. Box 403, La Plata, 1900, Argentina
}

Correspondence: Alejandro D. Bolzán

E-mail: abolzan@imbice.gov.ar or adbolzan64@gmail.com

Received: December 05, 2016

Published online: January 09, 2017

\begin{abstract}
Telomeres are specialized nucleoproteic complexes localized at the ends of eukaryotic chromosomes, that maintain their stability and integrity. They protect chromosome ends from fusion and from being recognized as sites of DNA damage, i.e., they distinguish natural DNA ends from DNA ends resulting from breakage events. In mammalian cells, telomeres consist of tandem arrays of the hexanucleotide TTAGGG, oriented 5' to $3^{\prime}$ towards the end of the chromosomes and associated proteins (the so-called "shelterin" complex), and a large non-coding RNA (named TERRA) which forms an integral component of telomeric heterochromatin. Telomere length is maintained by a dynamic process of telomere shortening and lengthening. Shortening can occur due to nucleolytic degradation and incomplete DNA replication due to the inability of lagging strand synthesis to completely replicate chromosomal ends (i.e., the "end replication problem"), whereas lengthening is primarily accomplished by the action of the enzyme telomerase and occasionally by the so-called Alternative Lengthening of Telomeres ("ALT") mechanism, which involves homologous recombination. The maintenance of telomere function is crucial for genomic stability and cell viability. Cells respond to dysfunctional telomeres by undergoing senescence, cell death, or genomic instability. Since telomeres play a fundamental role in maintaining chromosomal/genomic stability and telomerase activity and telomere lengthening play a key role in cancer development and progression, a proper knowledge of the effects of chemotherapeutic drugs on telomere length and telomerase activity in normal as well as tumor cells is of great importance to understand the genomic instability associated with chemotherapy regimens. Therefore, in this review we will summarize our current knowledge concerning the main data available about the effects of chemotherapeutic drugs on telomere length and telomerase activity in mammalian cells.
\end{abstract}

Keywords: Telomere; telomere length; telomerase; anticancer drugs; chemotherapeutic drugs

To cite this article: Alejandro D. Bolzán. Effect of chemotherapeutic drugs on telomere length and telomerase activity Telomere Telomerase 2016; 3: e1488. doi: 10.14800/tt.1488.

Copyright: (c) 2016 The Authors. Licensed under a Creative Commons Attribution 4.0 International License which allows users including authors of articles to copy and redistribute the material in any medium or format, in addition to remix, transform, and build upon the material for any purpose, even commercially, as long as the author and original source are properly cited or credited.

\section{Introduction}

Telomeres are specialized nucleoproteic complexes localized at the ends of eukaryotic chromosomes, that maintain their stability and integrity ${ }^{[1-3]}$. They protect chromosome ends from fusion and from being recognized as sites of DNA damage, i.e., they distinguish natural DNA from DNA ends resulting from breakage events ${ }^{[1-3]}$. 
In all vertebrates, telomeres are composed of tandem arrays of the hexanucleotide TTAGGG, oriented $5^{\prime} \rightarrow 3^{\prime}$ towards the end of the chromosome, ending in a $3^{\prime}$ single-stranded overhang ranging in length from $\sim 50$ to 400 $\mathrm{nt}^{[4-6]}$, bound by a specialized multiprotein complex known as "shelterin" [7], constituted by 6 proteins (POT1, TPP1. TIN2, TRF1, TRF2 and RAP1). Shelterin proteins are charged with protecting chromosome ends from activating a DNA damage response, inhibiting inappropriate repair mechanisms, and maintaining telomeric length and structure ${ }^{[7]}$. Telomeres also comprise (UUAGGG)n-containing RNA molecules (TERRA), a long non-coding RNA that is transcribed from telomeric DNA by RNA polymerase II ${ }^{[8-9]}$. TERRA has been implicated in several processes related to telomere function, including telomerase regulation, telomere chromatin organization and gene expression ${ }^{[8-10]}$.

Telomere length is maintained by a dynamic process of telomere shortening and lengthening. The telomeres are progressively lost with each round of cell division, losing approximately 20-300 bp of repeat sequences every cell division mainly due to the "end replication problem" (i.e., the inability of DNA polymerase to replicate DNA to the ends of linear chromosomes) ${ }^{[3]}$. This is the main mechanism for the loss of telomeric repeats and is termed replicative erosion or replicative shortening, which leads to replicative senescence of cells. Telomere erosion refers to a dysfunctional telomere (i.e., a telomere which has lost their end-capping function) which became critically short, so it cannot function properly. There is another kind of telomere shortening, termed "stress-dependent shortening", which is produced by stress-inducing factors like radiation, oncogenes, oxidative damage within telomeric DNA, and chromosome end-specific exonuclease activity ${ }^{[11-14]}$. Telomere shortening can promote genome instability, which may lead to cancer ${ }^{[3,}$ 15].

To avoid telomere shortening, some cells activate telomerase, a reverse transcriptase (i.e., a RNA dependent polymerase) that elongates chromosomes by adding TTAGGG sequences to the end of chromosomes. Telomerase is a ribonucleoprotein composed of dyskerin, the catalytic subunit termed TERT, and the RNA subunit named TERC, which serve as template to synthesize telomere DNA ${ }^{[3,10,16]}$. Although inactive in most somatic cells -with the exception of a transient $\mathrm{S}$ phase activity thought to maintain the single-stranded overhang- telomerase is active in immortal cell lines, germline cells, stem cells, activated lymphocytes, and most of the tumor cells analyzed so far ${ }^{[10,16]}$. Loss of telomerase enzymatic function leads to progressive telomere shortening over time, eventually resulting in the disappearance of detectable telomeric DNA and the formation of end-to-end chromosome fusions, followed by growth arrest or cell death $[10,16,17]$. In addition to telomere length maintenance, telomerase is also involved in other cellular processes not directly related to telomere function, including gene expression regulation, cell proliferation, apoptosis and cell signaling, adhesion and migration ${ }^{[10]}$. All these activities of telomerase are thought to contribute significantly to the process of carcinogenesis. In fact, telomerase upregulation or reactivation is a critical feature in over $90 \%$ of cancers ${ }^{[10]}$. Because of this, telomerase has been a prime target for the development of effective therapeutics against cancer ${ }^{[10]}$.

Telomere elongation can also occur in the absence of telomerase through the so-called ALT (for 'alternative lengthening of telomeres') mechanism, which involves homologous recombination between telomeres and has been described in several tumor cells and immortalized cell lines $[17,18]$. The ALT mechanism is employed by $10-15 \%$ of tumors ${ }^{[17,18]}$.

Many drugs used in conventional chemotherapy for the treatment of cancer induce genome instability and affect telomere function. Thus, several studies have shown that cancer patients treated with chemotherapeutic agents and radiation have shorter telomere in their blood cells, even after the end of the treatments ${ }^{[19-24]}$. Because telomere plays a critical role in regulating cellular life-span, aging and genomic stability, telomere shortening or erosion likely contributes to late side-effects occurring in long-term survivors of cancer patients. It has been suggested that repeated exposure to chemotherapy and radiotherapy may cause telomere dysfunction through which organ impairment and genomic instability take place ${ }^{[25]}$. Thus, telomere dysfunction will eventually contribute to undesirable side-effects in long-term survivors of cancer patients, such as the development of secondary tumors. Since telomeres play a fundamental role in maintaining chromosomal/genomic stability and telomerase activity and telomere lengthening play a key role in cancer development and progression ${ }^{[10]}$, a proper knowledge of the effects of chemotherapeutic drugs on telomere length and telomerase activity in normal as well as tumor cells is of great importance to understand the genomic instability associated with chemotherapy regimens. Therefore, in this review, we will summarize our current knowledge concerning the main data available about the effects of chemotherapeutic drugs on telomere length and telomerase activity in mammalian cells.

\section{Effect of chemotherapeutic drugs on telomere length and telomerase activity}

In this section, we will consider the main data available concerning the short- and long-term effects of chemotherapeutic drugs on telomere length and telomerase 
http://www.smartscitech.com/index.php/tt

Table 1. Effects of chemotherapeutic agents on telomere length and telomerase activity in mammalian cells

\begin{tabular}{|c|c|c|c|}
\hline Drug & Telomere length & Telomerase activity & Cell type and references \\
\hline \multirow[t]{6}{*}{ Bleomycin } & ND & -- & Chinese hamster cells $^{[32]}$ \\
\hline & $\downarrow \uparrow-(*)$ & $--\uparrow \downarrow(*)$ & $\begin{array}{l}\text { Rat cells (fibroblasts derived from dedifferentiated } \\
\text { adipose cells) }\end{array}$ \\
\hline & ND & $\uparrow$ & Rat cells (lung fibroblasts) ${ }^{[38]}$ \\
\hline & ND & $\uparrow$ & Mouse cells (lung epithelial cells) ${ }^{[37]}$ \\
\hline & ND & -- & Human testicular cancer cells ${ }^{[39]}$ \\
\hline & -- & -- & Mouse spermatogonial cells ${ }^{[40]}$ \\
\hline \multirow[t]{2}{*}{ Streptonigrin } & ND & -- & Chinese hamster cells ${ }^{[32]}$ \\
\hline & $\downarrow \uparrow-(*)$ & $\downarrow$ & $\begin{array}{l}\text { Rat cells (fibroblasts derived from dedifferentiated } \\
\text { adipose cells) }\end{array}$ \\
\hline \multirow[t]{2}{*}{ Streptozotocin } & ND & -- & Chinese hamster cells ${ }^{[33]}$ \\
\hline & $--\uparrow-(*)$ & -- & $\begin{array}{l}\text { Rat cells (fibroblasts derived from dedifferentiated } \\
\text { adipose cells) }{ }^{[36]}\end{array}$ \\
\hline \multirow[t]{4}{*}{ Paclitaxel } & $\downarrow$ & -- & Mouse melanoma cells ${ }^{[42]}$ \\
\hline & $\downarrow$ & -- & Paclitaxel-requiring mutant $\mathrm{CHO}$ cells ${ }^{[43]}$ \\
\hline & $\downarrow$ & $\downarrow$ & Human pharynx tumor cells ${ }^{[45]}$ \\
\hline & - & - & Human ovarian cancer cells ${ }^{[44]}$ \\
\hline Paclitaxel + AZT & $\downarrow$ & ND & Human pharynx tumor cells ${ }^{[46]}$ \\
\hline \multirow[t]{9}{*}{ Cisplatin } & $\downarrow$ & ND & Hela cells ${ }^{[51]}$ \\
\hline & ND & $\downarrow$ & Human testicular cancer cells ${ }^{[39]}$ \\
\hline & ND & $\downarrow$ & Human endometrial cancer cells ${ }^{[48]}$ \\
\hline & $\downarrow$ & $\downarrow$ & Mouse spermatogonial cells ${ }^{[40]}$ \\
\hline & $\downarrow$ & $\uparrow$ & Human ovarian cancer cells ${ }^{[44]}$ \\
\hline & $\downarrow$ & $\downarrow$ & Human hepatoma cells ${ }^{[49]}$ \\
\hline & ND & $\downarrow$ & Human ovarian cancer cells ${ }^{[50]}$ \\
\hline & ND & $\downarrow$ & $\begin{array}{l}\text { Human head and neck squamous cell carcinoma cell } \\
\text { lines }{ }^{[52]}\end{array}$ \\
\hline & ND & -- & Human haematopoietic cancer cell lines ${ }^{[53]}$ \\
\hline \multirow[t]{7}{*}{ Doxorubicin } & $\downarrow$ & $\downarrow$ & Human hepatoma cells ${ }^{[49]}$ \\
\hline & - & - & Human ovarian cancer cells ${ }^{[44]}$ \\
\hline & -- & $\downarrow$ & Human breast tumor cells ${ }^{[54]}$ \\
\hline & ND & $\downarrow$ & Human breast and stomach cancer cells ${ }^{[55]}$ \\
\hline & $\downarrow$ & $\downarrow$ & Human normal T-lymphocytes and fibroblasts ${ }^{[25]}$ \\
\hline & ND & $\downarrow$ & Human ovarian cancer cells ${ }^{[50]}$ \\
\hline & ND & - & Human testicular cancer cells ${ }^{[39]}$ \\
\hline \multirow[t]{9}{*}{ Etoposide } & -- & -- & Mouse spermatogonial cells ${ }^{[40]}$ \\
\hline & $\downarrow$ & $\uparrow$ & Human ovarian cancer cells ${ }^{[44]}$ \\
\hline & - & ND & $\begin{array}{l}\text { Human neuroblastoma and acute lymphoblastic } \mathrm{T} \\
\text { cells }{ }^{[58]}\end{array}$ \\
\hline & ND & -- & Human haematopoietic cancer cell lines ${ }^{[33]}$ \\
\hline & $\downarrow$ & $\downarrow$ & Human normal T-lymphocytes and fibroblasts ${ }^{[25]}$ \\
\hline & ND & $\uparrow$ & Human leukemic cells ${ }^{[59,60]}$ \\
\hline & ND & $\uparrow$ & Human pancreatic tumor cell lines ${ }^{[61]}$ \\
\hline & ND & $\downarrow$ & Human hepatomas and leukemic cell lines ${ }^{[62]}$ \\
\hline & ND & -- & Human nasopharyngeal carcinoma cells ${ }^{[63]}$ \\
\hline Etoposide + Doxorubicin & $\downarrow$ & ND & Human mesenchymal stem cells ${ }^{[56]}$ \\
\hline Etoposide + bleomycin + cisplatin & $\downarrow$ & ND & Rat male germ cells ${ }^{[57]}$ \\
\hline \multirow[t]{8}{*}{ Azydothimidine (AZT) } & $\downarrow$ & $\downarrow$ & Human lymphoid cell lines ${ }^{[65]}$ \\
\hline & $\downarrow$ & ND & Hela cells $^{[67]}$ \\
\hline & $\downarrow$ & $\downarrow$ & Human endometrial carcinoma cells ${ }^{[66]}$ \\
\hline & ND & $\downarrow$ & Mouse mammary carcinoma cells ${ }^{[68]}$ \\
\hline & ND & $\downarrow$ & Human pharynx cells ${ }^{[45]}$ \\
\hline & ND & $\downarrow$ & Human parathyroid cancer cells ${ }^{[69]}$ \\
\hline & ND & $\downarrow$ & Human liver carcinoma cells ${ }^{[70]}$ \\
\hline & ND & $\downarrow$ & Mouse mammary carcinoma cells ${ }^{[64]}$ \\
\hline AZT + arsenic trioxide & ND & $\downarrow$ & Human acute promyelocytic leukemia cells ${ }^{[72]}$ \\
\hline $\mathrm{AZT}+5-\mathrm{FU}$ & ND & $\downarrow$ & Human colon cancer cells ${ }^{[71]}$ \\
\hline \multirow[t]{2}{*}{ 5-Azacytidine } & $\downarrow$ & $\downarrow$ (expression of TERT) & Acute myeloid leukemia cells ${ }^{[75]}$ \\
\hline & $\stackrel{-}{--}$ & ND & Human glioblastoma cells ${ }^{[76]}$ \\
\hline 5-Aza-2'deoxycytidine \pm Trichostatin A & $\uparrow$ & ND & Breast cancer cells ${ }^{[74]}$ \\
\hline Gemcitabine & $\downarrow$ & -- & Hela cells ${ }^{[78]}$ \\
\hline $\mathrm{C}-1027$ & $\downarrow$ & ND & Human colon cancer cells ${ }^{[83]}$ \\
\hline \multirow[t]{2}{*}{ ICRF-193 } & $\downarrow$ & ND & Human osteosarcoma cells ${ }^{[85]}$ \\
\hline & -- & ND & Human colon carcinoma and cervical cancer cells ${ }^{[85]}$ \\
\hline
\end{tabular}


http://www.smartscitech.com/index.php/tt

$\begin{array}{llll}\text { Melphalan } & \mathrm{ND} & - & \begin{array}{l}\text { Human testicular cancer cells }{ }^{[39]} \\ \text { Mouse bone marrow cells }\end{array} \\ \text { 5-Fluorouracil (5-FU) } & \uparrow / \downarrow\left(^{(* * *)}\right. & \mathrm{ND} & \begin{array}{l}\text { Human head and neck squamous cell carcinoma cell } \\ \text { lines }\end{array} \\ & \mathrm{ND} & - & \text { Human colorectal carcinoma cells }^{[59]} \\ \text { 5-FU + Cisplatin } & \uparrow & \uparrow & \text { Human ovarian cancer cells } \\ \text { Cyclophosphamide } & \downarrow & \uparrow & \text { Mouse spermatogonial cells } \\ \text { 4OOH-CPA }(* *) & \downarrow & \downarrow & \text { Human haematopoietic cancer cell lines } \\ \text { Mitomycin C } & \mathrm{ND} & - & \text { Human testicular cancer cells } \\ \text { Methotrexate } & \mathrm{ND} & - & \end{array}$

$\uparrow$ : increasing effect (telomere elongation); $\downarrow$ : decreasing effect (telomere shortening or erosion); --: no effect; ND: Not determined. $\left({ }^{*}\right)$ These symbols represent the effects of the drug observed at $18 \mathrm{~h}, 10$ days and 15 days after treatment, respectively. (**) 4-hydroperoxycyclophosphamide, a preactivated analog of cyclophosphamide. (***) The increasing effect was observed in p53+/- mice, whereas the decreasing effect was observed in wild-type mice.

activity in mammalian cells. First, we will refer to those anticancer drugs whose effects on telomere length and telomerase activity have been intensively investigated and then we will focus on some anticancer drugs whose effects on these parameters are barely know. For a summary of the effects of each drug on telomere length and telomerase activity, the reader should refer to Table 1.

\section{Bleomycin, streptonigrin and streptozotocin}

Several years ago, we carried out a series of experiments to determine the effects of three antitumoral antibiotics, namely, bleomycin, streptonigrin and streptozotocin, on mammalian telomeres and telomeric sequences (see ${ }^{[26]}$ for review).

Bleomycin (CAS No. 11056-06-7) is a chemotherapeutic drug isolated from Streptomyces verticillus which is commonly used to treat testicular cancer, non-Hodgkin lymphoma, lung cancer, cervical cancer and cancers of the head and neck ${ }^{[27]}$. This antibiotic is a radiomimetic agent that generates free radicals and induces single- and double-strand breaks in DNA ${ }^{[27,28]}$. Streptonigrin (CAS No. 3930-19-6) is an aminoquinone antitumor antibiotic isolated from cultures of Streptomyces flocculus, which shows antitumor activity against a broad range of tumors, including breast, lung, head and neck cancer, lymphoma and melanoma [29], although its use in chemotherapy is very limited because the severe and prolonged bone marrow depression it induces [29]. Streptonigrin is also a venom of topoisomerase II, inhibiting this enzyme by stabilizing its transesterification intermediate (cleavable complex) ${ }^{[29]}$. Streptozotocin or streptozocin (CAS No. 18883-66-4) is an antibiotic isolated from Streptomyces achromogenes [30, 31], usually used to experimentally induce diabetes mellitus in rats, and considered a potential compound for the clinical treatment of some malignant diseases, specially advanced pancreatic neuroendocrine tumors and colon cancer. Also, streptozotocin is a potent alkylating agent that directly methylates DNA ${ }^{[30,31]}$.

Despite the abovementioned compounds induced chromosomal aberrations involving telomeres and interstitial telomeric sequences, none of them altered the activity of telomerase in $\mathrm{CHO}$ and $\mathrm{CHE}$ cells ${ }^{[32,33]}$, at least in the short-term (18 $\mathrm{h}$ after treatment). The effect of these drugs on telomere length in hamster cells was not determined. More recently, we investigated the long-term effect (i.e., up to 15 days after treatment) of bleomycin, streptonigrin and streptozotocin on telomeres of rat cells (the ADIPO-P2 cell line, derived from dedifferentiated adipose cells from Spragüe-Dawley rats) ${ }^{[34-36]}$. Bleomycin and streptonigrin had a variable effect on telomere length, since they both induced telomere shortening at $18 \mathrm{~h}$, telomere elongation at 10 days, and had no effect on telomere length at 15 days after treatment (Paviolo, unpublished). Nevertheless, these compounds had a completely different effect on telomerase activity. Bleomycin did not modify the activity of telomerase at $18 \mathrm{~h}$ after treatment (the same effect previously observed in Chinese hamster cells ${ }^{[32]}$ ), but produced an increase at 10 days and a decrease at 15 days after treatment ${ }^{[34]}$. Thus, bleomycin produced a delayed induction of telomerase activity in mammalian cells. This finding is in line with that of Fridlender et al. ${ }^{[37]}$ who found that this compound induces telomerase activity in lung epithelial cells of mice 7 and 14 days after treatment, and that of Nozaki et al. ${ }^{[38]}$, who found elevated levels of telomerase in fibroblasts and tissue extracts isolated from bleomycin-injured rat lungs at 7, 14, and 21 days postreatment, with maximal activity observed in the day 14 samples. Therefore, we concluded that the observed telomere instability induced by bleomycin in rat cells was unrelated to telomerase activity ${ }^{[34]}$.

On the contrary, streptonigrin induced a persistent inhibition of telomerase activity (up to 77\%) in streptonigrin-treated rat cells in comparison with that of untreated (control) rat cells at each time points analyzed (18 h, 10 days and 15 days after treatment). Therefore, telomerase could be involved in the observed telomere dysfunction in these cells (through the induction of telomere-related chromosomal aberrations ${ }^{[35]}$ ), but this assumption requires further studies to be confirmed. We previously observed in Chinese hamster cells that telomerase activity in streptonigrin-treated cells was similar to that of untreated cells $18 \mathrm{~h}$ after treatment ${ }^{[32]}$. Thus, the effect of 
streptonigrin on telomerase activity seems to be dependent on the cell type.

Concerning streptozotocin, we found that it also has a variable effect on telomere length in the long-term, since this drug had no significant effect at $18 \mathrm{~h}$ and 15 days after treatment, but induced telomere elongation at 10 days after treatment. These effects were not related with telomerase activity, which remained unchanged in both treated and untreated cells from $18 \mathrm{~h}$ to 15 days after treatment ${ }^{[36]}$. Therefore, the persistence of chromosomal aberrations related to telomere dysfunction observed in rat cells exposed to streptozotocin seems to be unrelated to telomerase activity or telomere length. The data registered in telomerase activity in the short-term agrees well with the data previously obtained in $\mathrm{CHO}$ cells, where no variations of the activity were observed $18 \mathrm{~h}$ posttreatment with streptozotocin ${ }^{[33]}$ in comparison to control (unexposed) cells.

Besides the abovementioned studies, other researchers reported additional data on the effect of bleomycin on telomere length and telomerase activity. Burger et al. showed that bleomycin inhibits telomerase activity in human testicular cancer cells ${ }^{[39]}$. Recently, Liu et al., studied the effect of bleomycin and other chemotherapeutic drugs on telomeres of a mouse spermatogonial cell line and found that this compound did not affect neither telomere length nor telomerase activity in these cells ${ }^{[40]}$. However, bleomycin induced telomere DNA damage in these cells, as seen by the colocalization of the telomere FISH probe signal with immunofluorescent $\gamma \mathrm{H} 2 \mathrm{AX}$ foci (a marker of DNA double-strand breaks) ${ }^{[40]}$. No further studies have been made concerning the effects of streptonigrin or streptozotocin on telomeres so far.

\section{Paclitaxel}

Paclitaxel or Taxol (CAS No. 33069-62-4) is an anticancer drug, isolated from the bark of the Pacific yew Taxus brevifolia, that has been shown to be clinically effective against ovarian, breast, lung, pancreatic, and other human cancers $^{[41]}$.

It has been shown that paclitaxel and its water-soluble forms poly (L-glutamic acid)-paclitaxel, sodium-pentetic acid-paclitaxel, and polyethylene glycol-paclitaxel, induced extensive telomere erosion (visualized as reduced telomeric signal intensity after telomere fluorescent in situ hybridization) in a murine metastatic melanoma cell line (K1735, clone X-21), but did not affect telomerase activity ${ }^{[42]}$. Similar results were also observed in Tax-18 and Tax-2-4, two paclitaxel-requiring mutant $\mathrm{CHO}$ cell lines ${ }^{[43]}$. Moreover, paclitaxel did not affect telomere length or telomerase activity in human ovarian cancer cells ${ }^{[44]}$. Interestingly, telomere erosion induced by paclitaxel can be enhanced by telomerase inhibitors, such as AZT, as demonstrated in human pharynx FaDu tumor cells ${ }^{[45,46]}$.

\section{Cisplatin}

Cisplatin (CAS No. 15663-27-1) is a well-known platinum-based anticancer drug with alkylating properties, which forms DNA adducts and induces apoptosis ${ }^{[47]}$. This compound is used alone or in combination with other chemotherapeutic agents for the clinical treatment of several types of cancers, including testicular, ovarian and lung cancer, among others ${ }^{[47]}$.

The inhibitory effect of cisplatin on telomerase activity was demonstrated in several types of cells, including human testicular cancer cells ${ }^{[39]}$, endometrial cancer cells ${ }^{[48]}$, hepatoma cells ${ }^{[49]}$, ovarian cancer cells ${ }^{[50]}$ and mouse spermatogonial cells ${ }^{[40]}$. In the study from Liu et al. ${ }^{[40]}$, it was also found that cisplatin shortens telomere length, thus causing telomere dysfunction. Thus, cisplatin could induce long-term telomeric loss in mammalian cells, resulting from the inhibition of the enzyme telomerase. Moreover, Ishibashi and Lippard ${ }^{[51]}$ by using Analysis of TRF Length (by Southern blot) showed that cisplatin induces telomere loss (shortening) and degradation in HeLa cells. Cisplatin was also found to induce telomere shortening in human hepatoma cells ${ }^{[49]}$ and human ovarian cancer cells ${ }^{[44]}$. However, the effect of cisplatin on telomerase activity in human ovarian cancer cells is not clear, since one study showed that this compound increases telomerase activity ${ }^{[4]}$, whereas another study showed that cisplatin inhibited telomerase activity in these cells ${ }^{[50]}$. Moreover, cisplatin was found to inhibit telomerase activity in human neck and head squamous cell carcinoma cell lines ${ }^{[52]}$. No effect of cisplatin on telomerase activity in human haematopoietic cancer cell lines was observed $^{[53]}$.

\section{Doxorubicin and etoposide}

Doxorubicin (also called Adriamycin, CAS No. 23214-92-8) and etoposide (CAS No. 33419-42-0) are both topoisomerase II inhibitors with anticancer properties. Doxorubicin inhibits telomerase activity in human testicular cancer cells ${ }^{[39]}$. It has been found that doxorubicin inhibits telomerase activity and shortens mean telomere length in human hepatoma cells ${ }^{[49]}$. Thus, it has been proposed that telomerase inhibition and telomere shortening by doxorubicin may contribute to its efficiency in the treatment of hepatocellular carcinoma. However, doxorubicin had no effect on telomerase or telomere length in human ovarian cancer cells ${ }^{[44]}$ or inhibited telomerase activity in these cells 
(cell line A2780) ${ }^{[50]}$, decreased telomerase activity but had no effect on telomere length in breast tumor cells ${ }^{[54]}$, and decreased telomerase activity in several human breast and stomach cancer cell lines ${ }^{[55]}$. Thus, the effect of doxorubicin on telomeres depends on the cell type.

A few years ago, it was reported that doxorubicin and etoposide induce progressive telomere shortening in human mesenchymal stem cells, obtained from bone marrow cells from normal adults and grown in the presence of platelet lysates ${ }^{[56]}$. A year later, Li et al. reported that the treatment of normal human $\mathrm{T}$ lymphocytes and fibroblasts with doxorubicin or etoposide led to significant shortening of telomeres, down-regulation of telomerase activity, diminished expression of TERT and the telomere binding proteins TPP1 and POT1 and telomere dysfunction in these cells ${ }^{[25]}$. However, recent data reported by Liu et al. showed that etoposide alone does not specifically affects telomeres of a mouse spermatogonial cell line and that this drug did not induce telomere dysfunction in these cells ${ }^{[40]}$, but in combination with bleomycin and cisplatin, etoposide produces telomere shortening in rat male germ cells ${ }^{[57]}$. In addition, it was demonstrated that etoposide did not affect telomere length in the neuroblastoma cell line SHSY5Y (with very short telomeres) or the acute lymphoblastic $\mathrm{T}$ cell line 1301 (which exhibits extremely long telomeres) ${ }^{[58]}$. Moreover, etoposide has no effect on telomerase activity in human haematopoietic cancer cell lines ${ }^{[53]}$ and induces telomere shortening and decreases telomerase activity in human ovarian cancer cells ${ }^{[44]}$. Upregulation of telomerase activity was observed in the human leukemic cell line HL60 ${ }^{[59,60]}$, and several pancreatic tumor cell lines after etoposide treatment ${ }^{[61]}$. However, a decrease in telomerase activity was observed in hepatocarcinomas and other leukemic cell lines ${ }^{[62]}$ and no change in levels of telomerase in nasopharyngeal carcinoma cells ${ }^{[63]}$. Thus, as with doxorubicin, the effect of etoposide on telomeres depends on the cell type.

\section{$A Z T$}

Azidothymidine or zidovudine (CAS No. 9003-98-9), is a thymidine analog used in the treatment of AIDS, that also exhibits anticancer effects ${ }^{[64]}$. It has been found that AZT inhibits telomerase activity and causes telomere shortening in human lymphoid cell lines (the B cell line JY616 and the T cell line Jurkat E6-1) ${ }^{[65]}$ and human endometrial carcinoma cells ${ }^{[66]}$, produces irreversible telomere shortening in Hela cells ${ }^{[67]}$, and inhibits telomerase activity in mouse mammary carcinoma cells ${ }^{[68]}$, human pharynx cells ${ }^{[45]}$, human parathyroid cancer cells ${ }^{[69]}$, human liver carcinoma cells ${ }^{[70]}$ and mouse mammary carcinoma cells ${ }^{[64]}$. In addition, AZT in combination with arsenic trioxide or 5-FU also inhibits telomerase activity in human colon cancer cells ${ }^{[71]}$ and acute promyelocytic leukemia cells ${ }^{[72]}$. Thus, AZT clearly inhibits telomerase activity in mammalian cells.

\section{$5-A Z A$}

5-azacytidine (5-AZA, Ladakamycin, CAS No. 320-67-2) and its deoxy derivative 5-aza-2'deoxycytidine (Decitabine, CAS No. 2353-33-5) are demethylating compounds (inhibit DNA methyltransferases) with anticancer properties, usually employed against myelodysplastic syndrome and acute myeloid leukemia ${ }^{[73]}$. It has been shown that 5-aza-2'deoxycytidine, either alone or in combination with trichostatin $\mathrm{A}$, induces telomere elongation in breast cancer cell lines due to up-regulation of shelterin genes ${ }^{[74]}$. In addition, 5-AZA was found to induce DNA damage at telomeres, telomere shortening, diminished TERT expression and apoptosis in acute myeloid leukemia cell lines ${ }^{[75]}$. Thus, it was suggested that another mechanism (besides DNA demethylation) by which 5-AZA exerts its antitumoral activity is telomere dysfunction ${ }^{[75]}$. On the contrary, Choudhury et al., using the glioblastoma cell line SF-767, found that 5-AZA caused significant changes in DNA methylation of subtelomeric regions of chromosomes but did not modify the telomere length in these cells ${ }^{[76]}$. Thus, further studies will be needed to clarify the effect of this compound on telomere length and telomerase activity.

\section{Gemcitabine}

It has been recently reported that the cytidine analog gemcitabine $\quad\left(2^{\prime}, 2^{\prime}\right.$-diflurodeoxycytidine) (CAS No. 95058-81-4), an effective anticancer drug against several types of solid tumors, including colorectal, breast, pancreatic, renal and lung cancers ${ }^{[77]}$, causes telomere attrition or shortening in Hela cells, by increasing the level and stability of TRF2 ${ }^{[99]}$. By increasing TRF2 expression, gemcitabine enhances the XPF activity, and because XPF is a nuclease, binding of this enzyme to telomeres may lead to inappropriate excision of telomeric DNA. The anticancer effect of gemcitabine is due to the incorporation of the active derivative compound $\mathrm{dFdCTP}$ into DNA in proliferating cells, leading to inhibition of DNA synthesis and repair. Thus, the above findings by $\mathrm{Su}$ et al. ${ }^{[78]}$ suggest that the promotion of telomere attrition by induction of TRF2 is a new mechanism of action of gemcitabine against cancer. This effect of gemcitabine seems to be independent of telomerase, since this drug had no effect on telomerase activity in Hela cells 3 days after treatment. No further studies have been made to analyze the effect of gemcitabine on telomere length or telomerase activity in mammalian cells.

C-1027 
The enediyne antibiotic C-1027 or Lidamycin (CAS No. 120177-69-7) is a new kind of macromolecular antitumor antibiotics, produced by Streptomyces globisporus in soil, consisting of a noncovalently bound apoprotein and a labile chromophore which is responsible for most of the biological activities ${ }^{[79-81]}$. This drug is a potent anticancer drug with radiomimetic properties, which is being currently evaluated in Phase II clinical trials ${ }^{[82]}$. Several years ago, it was demonstrated in cultured human colon carcinoma HCT116 cells exposed to $\mathrm{C}-1027$ that this drug induces telomere fusions (i.e., chromosomes joined end to end at their telomeres or fused together after complete loss of telomere sequences, as seen by telomere FISH) in these cells ${ }^{[83]}$. Therefore, C-1027 induces short-term telomere shortening in human cells. No further studies on the effects of C-1027 on telomere length or telomerase activity have been performed so far.

\section{ICRF-193}

ICRF-193 ([meso-2, 3-bis (2, 6-dioxopiperazin-4-yl) butane], CAS No. 21416-68-2) is a topoisomerase II catalytic inhibitor and a well-known anticancer drug for treating acute leukemia and lymphosarcoma ${ }^{[84]}$. It has been demonstrated that ICRF-193 causes telomere shortening in ALT cells (U2OS and Saos2 human osteosarcoma cell lines) but has no effect on telomere length in telomerase-positive cells (HCT116 human colon cancer cell line and Hela human cervical cancer cell line) ${ }^{[85]}$. Moreover, ICRF-193 causes ALT telomere shortening and inhibits ALT cell proliferation in mice ${ }^{[85]}$, which suggests that this drug could be used to prevent cell proliferation in cancer cells with an ALT mechanism of telomere elongation. No further studies on the effects of ICRF-193 on telomere length or telomerase activity have been performed so far.

\section{Melphalan}

Melphalan, L-phenylalanine mustard, L-PAM, Alkeran or L-Sarcolysine (CAS No. 148-82-3) is a chemotherapeutic drug belonging to the class of nitrogen mustard alkylating agents ${ }^{[86]}$. It has been reported that melphalan has no effect on telomerase activity in human testicular cancer cells ${ }^{[39]}$. More recently, by studying the induction and persistence of chromosome aberrations in bone marrow and spleen cells of p53+/- (and wild type) mice exposed for 4, 13, or 26 weeks to $2 \mathrm{mg} / \mathrm{kg}$ melphalan, Sgura et al. ${ }^{[87]}$ demonstrated that this compound induces telomere shortening in bone marrow cells of wild-type mice, while in p53+/- mice the exposure to this compound induces telomere elongation. No further studies on the effect of melphalan on telomere length or telomerase activity have been reported so far.

\section{$5-F U$}

In the case of 5-fluorouracil (CAS No. 51-21-8), a thymine analog with anticancer properties commonly used against several types of solid tumors, including breast, colorectal, pancreatic, skin and cervical carcinoma ${ }^{[88]}$, there is only a few reports about its effects on telomere length or telomerase activity. It has been shown that 5-FU inhibits telomerase activity in human head and neck squamous cell carcinoma cell lines ${ }^{[52]}$ and, combined with cisplatin, 5-FU increases telomerase activity and causes long-term telomere elongation in colorectal carcinoma cells (LoVo and DLD-1 cell lines) ${ }^{[89]}$.

\section{$C P A$}

Cyclophosphamide (CAS No. 50-18-0) is an alkylating drug with antitumoral properties, clinically used for the treatment of lymphoma, brain cancer, leukemia and some solid tumors, like cancer of the pancreas, and to induce Type 1 and 2 diabetes in laboratory animals ${ }^{[90]}$. Its clinical use is very limited due to its toxic effects. There are only a few data published concerning the effects of the anticancer drug cyclophosphamide on telomere length and telomerase activity. Decreased telomerase activity and telomere shortening were observed in mouse spermatogonial cells treated with the alkylating compound $4 \mathrm{OOH}-\mathrm{CPA}$ (a preactivated analog of CPA) ${ }^{[40]}$. CPA also induced telomere shortening in human ovarian cancer cells, but induced telomerase activity in these cells ${ }^{[44]}$.

\section{Mitomycin C and methotrexate}

The chemotherapeutic agents mitomycin C (CAS No. 50-07-7) and methotrexate (formerly amethopterin) (CAS No. 59-05-2) -used for the treatment of several types of cancer, including gastroinestinal cancers, breast cancer, bladder tumors, leukemias, lymphomas and lung cancerwere found to inhibit telomerase activity in human haematopoietic cancer cells and human testicular cancer cells, respectively ${ }^{[39,53]}$.

\section{Telomere length and telomerase activity alterations induced by chemotherapeutic drugs: Conclusions and future prospects.}

The studies reviewed here clearly show that telomere length and telomerase activity are differentially affected by exposure to chemotherapeutic drugs. However, from these studies and the analysis of data from Table 1, we can draw some important conclusions: 
1) For some chemotherapeutic drugs, their effect on telomere length and/or telomerase activity is clearly established. They induce telomere shortening and/or inhibit telomerase activity. Thus, cisplatin clearly causes telomere shortening and inhibits telomerase activity, paclitaxel induces telomere shortening, and doxorubicin and AZT inhibit telomerase activity. Moreover, streptozotocin do not alter telomerase activity, even in the long-term.

2) For other chemotherapeutic drugs (doxorubicin, 5-AZA, etoposide) contradictory data exist concerning their effects on telomere length and/or telomerase activity, so further studies are needed to clearly determine these effects.

3) For several chemotherapeutic drugs (gemcitabine, C-1027, ICRF-193, melphalan, 5-FU, CPA, mitomycin C, methotrexate) there is only a few data available regarding their effects on telomere length and telomerase activity, so further studies are needed to clearly establish whether they induce telomere shortening or lengthening and whether they induce up- or down-regulation of telomerase activity. Moreover, in the case of bleomycin, streptonigrin, streptozotocin, etoposide and AZT, their effect on telomere length is not clearly established yet.

Despite of the above conclusions, most of the studies performed so far have shown that chemotherapeutic drugs induce telomere shortening and inhibit telomerase activity. Therefore, the data available raise concern about the potential risks of a long-term chemotherapy based on the abovementioned drugs. Telomere shortening and/or telomerase inhibition induced by cytostatic therapy theoretically could induce an additional genomic instability in neoplastic cells, this effect causing undesirable side effects, including secondary malignancies in long-term survivors of cancer.

In summary, for most chemotherapeutic drugs, further studies will be needed to fully elucidate their effects on telomere length and telomerase activity. Depending on the drug, these studies should be aimed at determining whether it induces short- and long-term telomere shortening or elongation, or down- or up-regulation of telomerase activity. Undoubtedly, these studies will contribute to a better understanding of the effects of the anticancer drugs on mammalian cells, and this information will be of great importance to understand the genomic instability associated with chemotherapy regimens.

\section{Conflicting interests}

The authors have declared that no conflict of interests exist.

\section{Acknowledgements}

This work was supported by grants from the CONICET (Grant: PIP No. 0182), the Commission of Scientific Research of Buenos Aires Province (CICPBA), and the National University of La Plata (UNLP) of Argentina.

\section{Abbreviations}

TERRA: Telomeric repeat containing RNA; TERT: Telomerase Reverse Transcriptase; TERC: Telomerase RNA Component; ALT: Alternative lengthening of telomeres; CHO: Chinese hamster ovary cells; CHE: Chinese hamster embryo cells; FISH: Fluorescent in situ hybridization; TRF: Terminal Restriction Fragment; 4OOH-CPA: Hydroperoxycyclophosphamide; CPA: cyclophosphamide; AZT: 3'-azido-3'-deoxythymidine; 5-FU: 5-Fluorouracil; 5-AZA: 5-azacytidine; XPF: Xeroderma pigmentosum group F protein.

\section{References}

1. Zakian VA. Telomeres: beginning to understand the end. Science 1995; 270:1601-1607.

2. Blackburn EH. Switching and signaling at the telomere. Cell 2001; 106:661-673.

3. O'Sullivan RJ, Karlseder J: Telomeres: protecting chromosomes against genome instability. Nat Rev Mol Cell Biol 2010; 11:171-181.

4. Meyne J, Ratliff RL, Moyzis RK. Conservation of the human telomere sequence (TTAGGG)n among vertebrates. Proc Natl Acad Sci USA 1989; 86:7049-7053.

5. Meyne J, Baker RJ, Hobart HH, Hsu TC, Ryder OA, Ward OG, et al. Distribution of nontelomeric sites of (TTAGGG)n telomeric sequences in vertebrate chromosomes. Chromosoma 1990; 99:3-10.

6. Moyzis RK, Buckingham JM, Cram LS, Dani M, Deaven LL, Jones MD, et al. A highly conserved repetitive DNA sequence, (TTAGGG)n, present at the telomeres of human chromosomes. Proc Natl Acad Sci USA 1988; 85:6622-6626.

7. Schmutz I, de Lange T. Shelterin. Current Biology 2016; 26:R397-399.

8. Feuerhahn S, Iglesias N, Panza A, Porro A, Lingner J. TERRA biogenesis, turnover and implications for function. FEBS Lett 2010; 584:3812-3818.

9. Cusanelli E, Chartrand P. Telomeric repeat-containing RNA TERRA: a noncoding RNA connecting telomere biology to genome integrity. Front Genet 2015; 6:1-9.

10. Jafri MA, Ansari SA, Alqahtani MH, Shay JW. Roles of telomeres and telomerase in cancer, and advances in telomerase-targeted therapies. Genome Med 2016; 8:69.

11. von Zglinicki T, Saretzki G, Docke W, Lotze C. Mild hyperoxia shortens telomeres and inhibits proliferation of fibroblasts: a model for senescence? Exp Cell Res 1995; 220:186-193. 
12. Kawanishi S, Oikawa S. Mechanism of telomere shortening by oxidative stress. Ann N Y Acad Sci 2004; 1019:278-284.

13. Blasco MA, Lee HW, Hande MP, Samper E, Lansdorp PM, DePinho RA, et al. Telomere shortening and tumor formation by mouse cells lacking telomerase RNA. Cell 1997; 91:25-34.

14. Ayouaz A, Raynaud C, Heride C, Revaud D, Sabatier L. Telomeres: Hallmarks of radiosensitivity. Biochimie 2008; 90:60-72.

15. Murnane JP. Telomere dysfunction and chromosome instability. Mutat Res 2012; 730:28-36.

16. $\mathrm{Xu} \mathrm{Y,} \mathrm{Goldkorn} \mathrm{A.} \mathrm{Telomere} \mathrm{and} \mathrm{telomerase} \mathrm{therapeutics} \mathrm{in}$ cancer. Genes 2016; 7:22.

17. Zhao Z, Pan X, Liu L, Liu N. Telomere length maintenance, shortening, and lengthening. J Cell Physiol 2014; 229:1323-1329.

18. Draskovic I, Londono-Vallejo A. Telomere recombination and the ALT pathway: a therapeutic perspective for cancer. Curr Pharm Des 2014; 20:6466-6471.

19. Engelhardt M, Ozkaynak MF, Drullinsky P, Sandoval C, Tugal O, Jayabose $\mathrm{S}$, et al. Telomerase activity and telomere length in pediatric patients with malignancies undergoing chemotherapy. Leukemia 1998; 12:13-24.

20. Franco S, Ozkaynak MF, Sandoval C, Tugal O, Jayabose S, Engelhardt $\mathrm{M}$, et al. Telomere dynamics in childhood leukemia and solid tumors: a follow-up study, Leukemia 2003; 17:401-410.

21. Lee JJ, Nam CE, Cho SH, Park KS, Chung IJ, Kim HJ. Telomere length shortening in non-Hodgkin's lymphoma patients undergoing chemotherapy. Ann Hematol 2003; 82:492-495.

22. Ricca I, Compagno M, Ladetto M, Rocci A, Dell'Aquila M, Omedè $\mathrm{P}$, et al. Marked telomere shortening in mobilized peripheral blood progenitor cells (PBPC) following two tightly spaced high-dose chemotherapy courses with G-CSF. Leukemia 2005; 19:644-651.

23. Schröder CP, Wisman GB, de Jong S, van der Graaf WT, Ruiters $\mathrm{MH}$, Mulder NH, et al. Telomere length in breast cancer patients before and after chemotherapy with or without stem cell transplantation. Br J Cancer 2001; 84:1348-1353.

24. Unryn BM, Hao D, Gluck S, Riabowol KT. Acceleration of telomere loss by chemotherapy is greater in older patients with locally advanced head and neck cancer. Clin Cancer Res 2006; 12:6345-6350.

25. Li P, Hou M, Lou F, Björkholm M, Xu D. Telomere dysfunction induced by chemotherapeutic agents and radiation in normal human cells. Int J Biochem Cell Biol 2012; 44:1531-1540.

26. Bolzán AD. Chromosomal aberrations involving telomeres and interstitial telomeric sequences. Mutagenesis 2012; 27:1-15.

27. Chen J, Stubbe J. Bleomycins: towards better therapeutics. Nat Rev Cancer 2005; 5:102-112.

28. Povirk LF, Austin MJ. Genotoxicity of bleomycin. Mutat Res 1991; 257:127-143.

29. Bolzán AD, Bianchi MS. Genotoxicity of streptonigrin: a review. Mutat Res 2001; 488:25-37.

30. Bolzán AD, Bianchi MS. Genotoxicity of streptozotocin. Mutat Res 2002; 512:121-134.

31. Bolzán AD. Genotoxic effects of Streptozotocin. In
Streptozotocin: Uses, Mechanism of Action and Side Effects. 1st edition. Edited by Gauthier EL. New York: Nova Science Publishers Inc.; 2014:99-120.

32. Bolzán AD, Páez GL, Bianchi MS. FISH analysis of telomeric repeat sequences and their involvement in chromosomal aberrations induced by radiomimetic compounds in hamster cells. Mutat Res 2001; 479:187-196.

33. Quiroga IY, Paviolo NS, Bolzán AD. Interstitial telomeric sequences are not preferentially involved in the chromosome damage induced by the methylating compound streptozotocin in Chinese hamster cells. Environ Mol Mutagen 2013; 54:147-152.

34. Paviolo NS, Quiroga IY, Castrogiovanni DC, Bianchi MS, Bolzán AD. Telomere instability is present in the progeny of mammalian cells exposed to bleomycin. Mutat Res 2012; 734:5-11.

35. Paviolo NS, Castrogiovanni DC, Bolzán AD. The radiomimetic compound streptonigrin induces persistent telomere dysfunction in mammalian cells. Mutat Res 2014; 760:16-23.

36. Paviolo NS, Santiñaque FF, Castrogiovanni DC, Folle GA, Bolzán $\mathrm{AD}$. The methylating agent streptozotocin induces persistent telomere dysfunction in mammalian cells. Mutat Res 2015; 794:17-24.

37. Fridlender ZG, Cohen PY, Golan O, Arish N, Wallach-Dayan S, Breuer R. Telomerase activity in bleomycin-induced epithelial cell apoptosis and lung fibrosis. Eur Respir J 2007; 30:205-213.

38. Nozaki Y, Liu T, Hatano K, Gharaee-Kermani M, Phan SH. Induction of telomerase activity in fibroblasts from bleomycin-injured lungs. Am J Respir Cell Mol Biol 2000; $23: 460-465$.

39. Burger AM, Double JA, Newell DR. Inhibition of telomerase activity by cisplatin in human testicular cancer cells. Eur J Cancer 1997; 33:638-644.

40. Liu M, Hales BF, Robaire B. Effects of four chemotherapeutic agents, bleomycin, etoposide, cisplatin, and cyclophosphamide, on DNA damage and telomeres in a mouse spermatogonial cell line. Biol Reprod 2014; 90:1-10.

41. Mekhail TM, Markman M. Paclitaxel in cancer therapy. Expert Opin Pharmacother 2002; 3:755-766.

42. Multani AS, Li C, Ozen M, Imam AS, Wallace S, Pathak S. Cell-killing by paclitaxel in a metastatic murine melanoma cell line is mediated by extensive telomere erosion with no decrease in telomerase activity. Oncol Rep 1999; 6:39-44.

43. Multani AS, Chandra J, Mcconker J, Sen S, Cabral TF, Pathak S. Cell death in paclitaxel-dependent chinese hamster ovary cells is initiated by the loss of telomeric DNA repeats. Oncol Res 1999; 11:455-460.

44. Kiyozuka Y, Yamamoto D, Yang J, Uemura Y, Senzaki H, Adachi $\mathrm{S}$, et al. Correlation of chemosensitivity to anticancer drugs and telomere length, telomerase activity and telomerase RNA expression in human ovarian cancer cells. Anticancer Res 2000; 20:203-212.

45. Mo Y, Gan Y, Song S, Johnston J, Xiao X, Wientjes MG, et al. Simultaneous targeting of telomeres and telomerase as a cancer therapeutic approach. Cancer Res 2003; 63:579-585.

46. Johnston JS, Johnson A, Gan Y, Wientjes MG, Au JL. Synergy between 3'-azido-3'-deoxythymidine and paclitaxel in human pharynx FaDu cells. Pharm Res 2003; 20:957-961. 
47. Schmitt SM, Frezza M, Dou QP. New applications of old metal-binding drugs in the treatment of human cancer. Front Biosci (Schol Ed) 2012; 4:375-391.

48. Błasiak J, Kadłubek M, Kowalik J, Romanowicz-Makowska H, Pertyński $\mathrm{T}$. Inhibition of telomerase activity in endometrial cancer cells by selenium-cisplatin conjugate despite suppression of its DNA-damaging activity by sodium ascorbate. Teratog Carcinog Mutagen 2002; 22:73-82.

49. Zhang RG, Guo LX, Wang XW, Xie H. Telomerase inhibition and telomere loss in BEL-7404 human hepatoma cells treated with doxorubicin. World J Gastroenterol 2002; 8:827-831.

50. Kunifuji Y, Gotoh S, Abe T, Miura M, Karasaki Y. Down-regulation of telomerase activity by anticancer drugs in human ovarian cancer cells. Anticancer Drugs 2002; 13:595-598.

51. Ishibashi T, Lippard SJ. Telomere loss in cells treated with cisplatin. Proc Natl Acad Sci USA 1998; 95:4219-4223.

52. Lee BJ, Lee BH, Wang SG, Lee JC, Roh HJ, Goh EK, et al. Change of the expression of human telomerase reverse transcriptase mRNA and human telomerase RNA after cisplatin and 5-fluorouracil exposure in head and neck squamous cell carcinoma cell lines. J Korean Med Sci 2007; 22 Suppl:S73-78.

53. Akiyama M, Horiguchi-Yamada J, Saito S, Hoshi Y, Yamada O, Mizoguchi $\mathrm{H}$, et al. Cytostatic concentrations of anticancer drugs do not affect telomerase activity of leukaemic cells in vitro. Eur J Cancer 1999, 35:309-315.

54. Elmore LW, Rehder CW, Di X, McChesney PA, Jackson-Cook CK, Gewirtz DA, et al. Adriamycin-induced senescence in breast tumor cells involves functional p53 and telomere dysfunction. J Biol Chem 2002; 277:35509-35515.

55. Park KH, Rha SY, Kim CH, Kim TS, Yoo NC, Kim JH, et al. Telomerase activity and telomere lengths in various cell lines: changes of telomerase activity can be another method for chemosensitivity evaluation. Int J Oncol 1998; 13:489-495.

56. Buttiglieri S, Ruella M, Risso A, Spatola T, Silengo L, Avvedimento EV, et al. The aging effect of chemotherapy on cultured human mesenchymal stem cells. Exp Hematol 2011; 39:1171-1181.

57. Liu M, Maselli J, Hales BF, Robaire B. The effects of chemotherapy with bleomycin, etoposide, and cis-platinum on telomeres in rat male germ cells. Andrology 2015; 3:1104-1112.

58. Jeyapalan J, Leake A, Ahmed S, Saretzki G, Tilby M, von Zglinicki T. The role of telomeres in Etoposide induced tumor cell death. Cell Cycle 2004; 3:1169-1176.

59. Moriarty TJ, Dupuis S, Autexier C. Rapid upregulation of telomerase activity in human leukemia HL-60 cells treated with clinical doses of the DNA damaging drug etoposide. Leukemia 2002; 16:1112-1120.

60. Klapper W, Qian W, Schukte C, Parwaresch R. DNA damage transiently increases TRF2 mRNA expression and telomerase activity. Leukemia 2003; 17:2007-2015.

61. Sato N, Mizumoto K, Nishio S, Maehara N, Urashima T, Ogawa $\mathrm{T}$, et al. Up-regulation of telomerase activity in human pancreatic cancer cells after exposure to etoposide. Br J Cancer 2000; 82:1819-1826.

62. Li D, Zhang Y, Cao W, Sun L, Xu H, Lu W. Regulative function of telomerase and extra- cellular regulated protein kinases to leukemic cell apoptosis. J Huazhong Univ Sci Technolog Med Sci 2002; 22:292-301.

63. $\mathrm{Ku} \mathrm{WC}$, Cheng AJ, Wang TC. Inhibition of telomerase activity by PKC inhibitors in human nasoparyngeal cancer cells in culture. Biochem Biophys Res Comm 1997; 241:730-736.

64. Armando RG, Gómez DM, Gómez DE. AZT exerts its antitumoral effect by telomeric and non-telomeric effects in a mammary adenocarcinoma model. Oncol Rep 2016; 36:2731-2736.

65. Strahl C, Blackburn EH. Effects of reverse transcriptase inhibitors on telomere length and telomerase activity in two immortalized human cell lines. Mol Cell Biol 1996; 16:53-65.

66. Murakami J, Nagai N, Shigemasa K, Ohama K. Inhibition of telomerase activity and cell proliferation by a reverse transcriptase inhibitor in gynaecological cancer cell lines. Eur J Cancer 1999; $35: 1027-1034$.

67. Gomez DE, Tejera AM, Olivero OA. Irreversible telomere shortening by $3^{\prime}$-azido-2',3'-dideoxythymidine (AZT) treatment. Biochem Biophys Res Commun 1998; 246:107-110.

68. Tejera AM, Alonso DF, Gomez DE, Olivero OA. Chronic in vitro exposure to 3'-azido-2', 3'-dideoxythymidine induces senescence and apoptosis and reduces tumorigenicity of metastatic mouse mammary tumor cells. Breast Cancer Res Treat 2001; 65:93-99.

69. Falchetti A, Franchi A, Bordi C, Mavilia C, Masi L, Cioppi F, et al. Azidothymidine induces apoptosis and inhibits cell growth and telomerase activity of human parathyroid cancer cells in culture. Bone Miner Res 2005; 20:410-418.

70. Chen C, Zhang Y, Wang Y, Huang D, Xi Y, Qi Y. Synergic effect of 3'-azido-3'-deoxythymidine and arsenic trioxide in suppressing hepatoma cells. Anticancer Drugs 2011; 22:435-443.

71. Brown T, Sigurdson E, Rogatko A, Broccoli D. Telomerase inhibition using azidothymidine in the HT-29 colon cancer cell line. Ann Surg Oncol 2003; 10:910-915.

72. Hassani S, Ghaffari SH, Zaker F, Mirzaee R, Mardani H, Bashash $\mathrm{D}$, et al. Azidothymidine hinders arsenic trioxide-induced apoptosis in acute promyelocytic leukemia cells by induction of p21 and attenuation of G2/M arrest. Ann Hematol 2013; 92:1207-1220.

73. Christman JK. 5-Azacytidine and 5-aza-2'-deoxycytidine as inhibitors of DNA methylation: mechanistic studies and their implications for cancer therapy. Oncogene 2002; 21:5483-5495.

74. Motevalli A, Yasaei H, Virmouni SA, Slijepcevic P, Roberts T. The effect of chemotherapeutic agents on telomere length maintenance in breast cancer cell lines. Breast Cancer Res Treat 2014; 145:581-591.

75. Zhang X, Li B, de Jonge N, Björkholm M, Xu D. The DNA methylation inhibitor induces telomere dysfunction and apoptosis of leukemia cells that is attenuated by telomerase over-expression. Oncotarget 2015; 6:4888-4900.

76. Choudhury SR, Cui Y, Milton JR, Li J, Irudayaraj J. Selective increase in subtelomeric DNA methylation: an epigenetic biomarker for malignant glioma. Clin Epigenetics 2015; 7:107.

77. Grindey GB, Hertel LW, Plunkett W. Cytotoxicity and antitumor activity of 2',2'-difluorodeoxycytidine (Gemcitabine). Cancer Invest 1990; 8:313.

78. Su CH, Chu WC, Lan $\mathrm{KH}$, Li CP, Chao Y, Lin $\mathrm{HC}$, et al. Gemcitabine causes telomere attrition by stabilizing TRF2. Eur J 
Cancer 2012; 48:3465-3474.

79. Hu JL, Xue YC, Xie MY, Zhang R, Otani T, Minami Y, et al. A new macromolecular antitumor antibiotic, C-1027. I. Discovery, taxonomy of producing organism, fermentation and biological activity. J Antibiot (Tokyo) 1988; 41:1575-1579.

80. Otani T, Minami Y, Marunaka T, Zhang R, Xie MY. A new macromolecular antitumor antibiotic, C-1027. II. Isolation and physico-chemical properties. J Antibiot (Tokyo) 1988; 41:1580-1585.

81. Zhen YS, Ming XY, Yu B, Otani T, Saito H, Yamada Y. A new macromolecular antitumor antibiotic, C-1027. III. Antitumor activity. J Antibiot (Tokyo) 1989; 42:1294-1298.

82. Chen Y, Yu D, Zhang C, Shang B, He H, Chen J, et al. Lidamycin inhibits tumor initiating cells of hepatocellular carcinoma Huh7 through GSK3 $\beta / \beta$-catenin pathway. Mol Carcinog 2015; 54:1-8.

83. McHugh MM, Gawron LS, Matsui S, Beerman TA. The antitumor enediyne C-1027 alters cell cycle progression and induces chromosomal aberrations and telomere dysfunction. Cancer Res 2005; 65:5344-5351.

84. Downes CS, Clarke DJ, Mullinger AM, Giménez-Abián JF, Creighton AM, Johnson RT. A topoisomerase II-dependent G2 cycle checkpoint in mammalian cells. Nature 1994; 372:467-470.
85. Hsieh MH, Tsai CH, Lin CC, Li TK, Hung TW, Chang LT, et al. Topoisomerase II inhibition suppresses the proliferation of telomerase-negative cancers. Cell Mol Life Sci 2015; $72: 1825-1837$

86. Dronkert ML, Kanaar R. Repair of DNA interstrand cross-links. Mutat Res 2001; 486:217-247.

87. Sgura A, De Amicis A, Stronati L, Cinelli S, Pacchierotti F, Tanzarella C. Chromosome aberrations and telomere length modulation in bone marrow and spleen cells of melphalan-treated p53+/- mice. Environ Mol Mutagen 2008; 49:467-475.

88. Malet-Martino M, Martino R. Clinical studies of three oral prodrugs of 5-fluorouracil (capecitabine, UFT, S-1): a review. Oncologist 2002; 7:288-323.

89. Kuranaga N, Shinomiya N, Mochizuki H. Long-term cultivation of colorectal carcinoma cells with anti-cancer drugs induces drug resistance and telomere elongation: an in vitro study. BMC Cancer $2001 ; 1: 10$.

90. Huttunen KM, Raunio H, Rautio J. Prodrugs--from serendipity to rational design. Pharmacol Rev 2011; 63: 750-771. 